\title{
Level of Unintended Pregnancy and its Associated Factors among Currently Pregnant Women in Duguna Fango District, Wolaita Zone, Southern Ethiopia
}

\section{Firehiwot Danssa Getachew}

Gender Specialist, NGO, 500 Wolaita Sodo, ETHIOPIA

${ }^{*}$ Correspondence (Email):

firedanssa@gmail.com

\begin{abstract}
Few researchers in Ethiopia have studied issues related to unintended pregnancy and little has been discussed about its cause especially in the rural parts of the county. Moreover, efforts to reduce the incidence of unintended pregnancy were very weak. Hence, there is a continued need for research, information sharing and documentation of efforts aimed at reducing unintended pregnancy. Hence the objective of this study is to measure the level of unintended pregnancy and identify associated factors among currently pregnant women in Duguna Fango Woreda, Wolaita Zone, South Ethiopia. Facility based Cross-sectional study method were instrumental under current study. Four hundred Seventy Seven (477) respondents were selected by systematic random sampling method from five health centers. Data collected through structured and pre-tested questionnaire, and analyzed using SPSS for windows version 16.0. Bivariate and multivariate logistic analysis was used to calculate the odds ratios with $95 \%$ confidence interval for the different risk factors. The level of significance was set at $\mathrm{P}<0.05$. It is concluded that, unintended pregnancy was found to be a major reproductive health problem in the study area and thus deserves priority attention. It is recommended that, different partners in partnership with the government to address the issue of improving income among women, improving their perception, empowerment, economic status and women on reproductive health issues is encouraged.
\end{abstract}

Key words: Pregnancy, Unwanted Pregnancy, Contraception

\section{INTRODUCTION}

Literatures of various studies describe the concepts of unintended or unplanned pregnancy in different ways. It refers to the sum of mistimed and unwanted pregnancies. A woman is assumed to have a mistimed pregnancy, if she became pregnant at the time when she did not want to. On the other hand, a woman is assumed to have an unwanted pregnancy if the woman did not want to become pregnant at all, or in other words, the pregnancy occurred when she wanted to have no more children (Central Statistical Agency of Nigeria, 2008).

Few researchers in Ethiopia have studied issues related to unintended pregnancy and little has been discussed about its cause especially in the rural parts of the county (Akale, 2008). Moreover, efforts to reduce the incidence of unintended pregnancy were very weak. Hence, there is a continued need for research, information sharing and documentation of efforts aimed at reducing unintended pregnancy.

Maternal mortality is a substantial burden in the world and it has received recognition at the global level as one of the millennium Development Goals (United Nations, 2008). Still now maternal mortality remains a main challenge to worldwide according to assessment of maternal mortality in 180 countries in 2010, it was estimated to be 287,900 maternal deaths annually worldwide. Developing country account about $99 \%(284,000)$ of global maternal death and more than half $(162,000)$ of all maternal deaths were in sub-Saharan Africa. At the country level, India $(56,000)$, 
Nigeria $(40,000)$, Democratic republic of Congo $(15,000)$, Pakistan $(12,000)$, Sudan $(10,000)$, Indonesia $(9,600)$, Ethiopia $(9,000)$, united republic of Tanzania $(8,500)$, Bangladesh $(7,200)$ and Afghanistan $(6,400)$, these 10 countries comprised $60 \%$ of the global maternal death reported in 2010 (WHO, 2010). It is infer that, the lion share of the maternal mortality is the major challenges of developing countries like Ethiopia.

\section{Statement of the Problem}

This research investigates the level of unintended pregnancy and associated factors among Deguna Fango Woreda currently pregnant women. Unintended pregnancy is a worldwide problem and it affects women in both developing as well as developed societies. Globally, $38 \%$ of pregnancies are unintended (Kaye, 2006). One of the objectives of the United Nations Millennium Development Goals (MDGs) was to reduce MMR by an average of $5.5 \%$ every year over the period $1990-2015$.

At the global level, MMR decreased by less than $5.5 \%$ to reach the target of MDG (Siddhartha, 2010). Of all 8 MDGs, countries have made the least progress toward maternal mortality reduction. Most Sub- Saharan African countries are not on track for meeting the targets pertaining to MMR. Recent estimates suggest that the average annual rate of reduction in MMR in SSA countries is less than 1\% (US Global Health Policy, 2010).

Each year about 184 million pregnancies occur in the developing world, and 40 percent of these are unintended (Bongaarts and Sinding, 2011). It is estimated that about half of the unintended pregnancies ended in abortion, which is responsible for at least one in seven maternal deaths worldwide (Singh etal, 2010). More than 95 percent of these deaths occur in developing countries (Ciment, 1999). In addition, unintended pregnancy leads to increase risk of maternal depression and has negative effect on antenatal care, breastfeeding and infant mortality (Gipson etal, 2008).

In developing countries, many women are at risk for unwanted pregnancies because contraception is not used for various reasons (Fantahun etal, 1995). In Ethiopia, the use of modern methods of contraception to prevent unwanted pregnancy has been advocated for the last 50 years. However, recent reports depict that; the contraceptive prevalence rate is $23 \%$ in this country, which is one of the lowest in the world (Federal Democratic Republic of Ethiopia, 2004). When women are able to access modern methods of contraception, pregnancy can occur after failure of the contraceptive method (Kabir, 1989).

In addition, other reports (Alan, 2006) portray that; forced sexual inter-course also contributes to a significant number of unwanted pregnancies. Hence, unwanted pregnancy continues to be very common and poses a great challenge to maternal health. Previous reports from Ethiopia revealed that un-safe abortion is one of the major causes of maternal death. However, efforts to reduce the incidence of unwanted pregnancy were not successful. There is a need of further study to understand the causes of unwanted pregnancy and its impact on maternal health which may help to develop new strategies to deal with unwanted pregnancies (Gessessew, 2010). Hence, this paper aimed to measure the level of unintended pregnancy and associated factors with it among currently pregnant women in Deguna Fango Woreda, Wolaita zone, SNNPR, Ethiopia. Consequently, the results of this study can be used as inputs for family planning program implementation, and thereby increasing the chance of health outcomes for both mothers and their infants.

\section{RATIONALE OF THE STUDY}

In Ethiopia, high levels of maternal mortality which account for 676 per 100,000 live births from EDHS, 2011 report which remains major public health challenge and this is not significantly different from EDHS, 2005 report MMR 673 per 100,000 live births (Central Statistical Agency, 2011).

Over 100 million acts of sexual intercourse take place each day in the world, resulting around 1 million conceptions, about $50 \%$ of which are unplanned and about $25 \%$ are definitely unwanted. The World Health Report (Regassa and Kebede, 2011) noted that unwanted, mistimed and unintended pregnancy is the most common cause of maternal mortality in developing countries. In Africa, the very high rate of unintended pregnancy in 1995, which was 92 per 1000 women, declined only slightly by 2008 , to 86 per 1,000 . The unintended pregnancy rate is much higher in Eastern Africa (118 per 1,000 women of child bearing age) and middle Africa (94 per 1,000) than in the other three sub regions: Northern, Southern and Western Africa, where the rate ranges between 56 and 83 per

1,000 (Singns, 2009). Therefore, this study was carried out to determine the level of unintended pregnancy and associated factors among selected currently pregnant women in one of the rural districts of Southern Ethiopia, Deguna Fango.

\section{Conceptual Framework}

Conceptual framework described as "a skeletal structure of justification, rather than a skeletal structure of explanation" (p. 210). A conceptual framework is an argument that the concepts chosen for investigation, and any anticipated relationships among them, will be appropriate and useful given the research problem under investigation (Eisenhart, 1991). 
The framework used may be based on different theories and various aspects of practitioner knowledge, depending on what the researcher can argue will be relevant and important to address about a research problem.

Figure 1 indicates the conceptual framework that was developed based on the literature review. The framework indicates the relationship between dependent variable (unintended pregnancy) and independent variables that could predict the outcome.

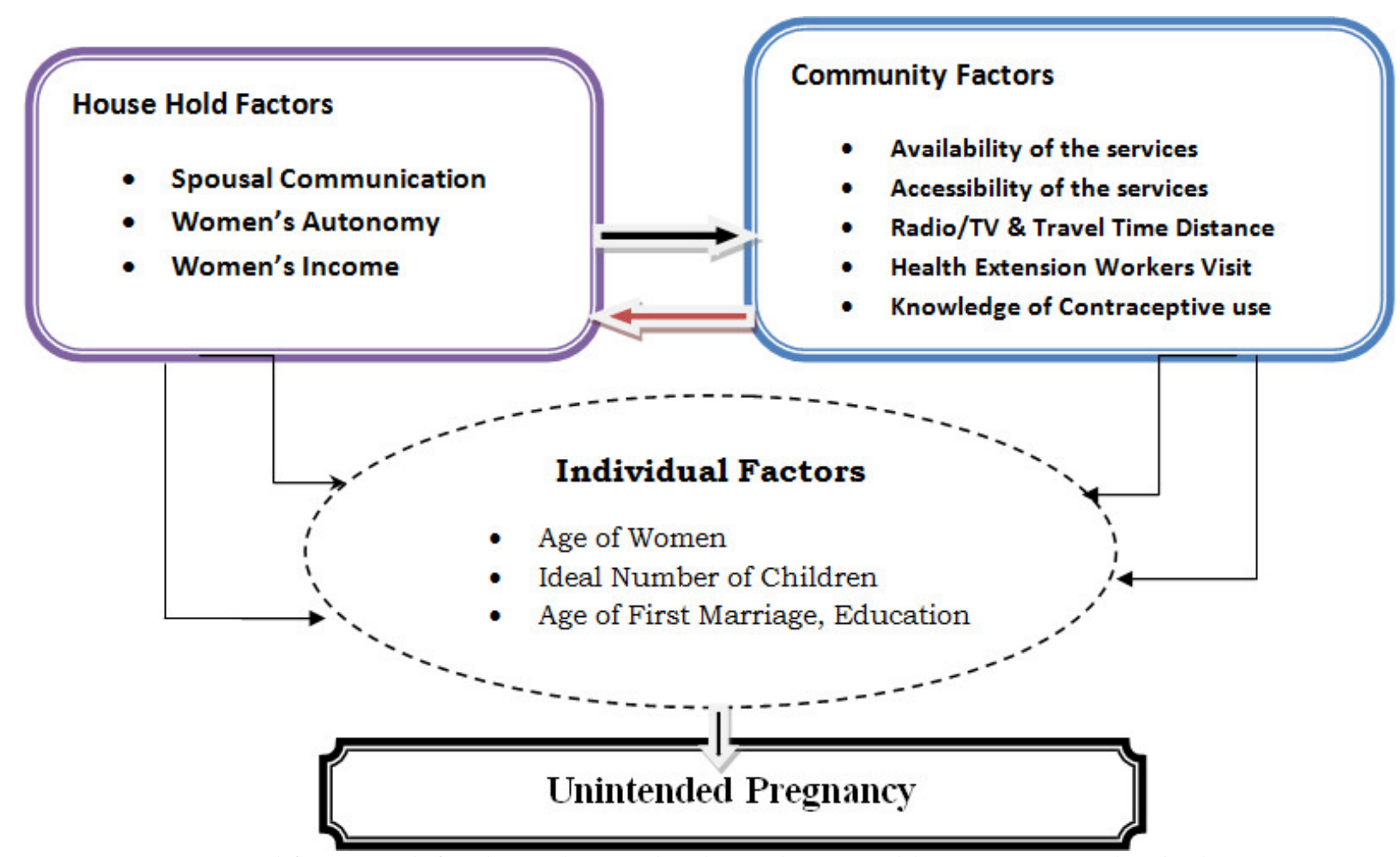

Figure 1: Conceptual framework for dependent and independent variables. (Regassa and Kebede, 2011)

\section{RESEARCH Questions}

On light of the above challenges the following basic questions formulated and treated accordingly. This research answered the question:

1. What was the level of unintended pregnancy among currently pregnant women in Deguna Fango Woreda of Wolaita Zone, Southern Nation Nationalities and Peoples Region, Ethiopia?

2. What factors are associated with unintended pregnancy among currently pregnant women in Deguna Fango Woreda of Wolaita Zone, Southern Nation Nationalities and Peoples Region?

\section{ObJectives}

The study consists of one general objective and two specific objectives. General objective is to measure the level of unintended pregnancy and its associated factors among currently pregnant women in Deguna Fango Woreda Wolaita Zone, SNNPR,Ethiopia. Specific objectives are:

- To determine the level of unintended pregnancy.

- To identify the associated factors of unintended pregnant.

\section{RESEARCH DESIGN AND METHODS}

\section{Study Area}

The study was conducted in Deguna Fango Woreda, Wolaita Zone, and SNNPR State. In the Woreda the agro ecologic zone divided into three, Dega - area coverage is $22 \%$, Woyena Dega - area coverage is $26 \%$, and Kolla - area coverage is $52 \%$. Subsistence crop production is the main livelihood strategy followed by livestock husbandry. The Woreda is one of the twelve Woredas of Wolaita zone which is located $400 \mathrm{~km}$ to south from Addis Ababa, $64 \mathrm{~km}$ to south west from Hawassa and $44 \mathrm{~km}$ to east from Wolaita Sodo as Woreda Finance and Economy report of 2013 


\section{Map of Wolayta Zone}

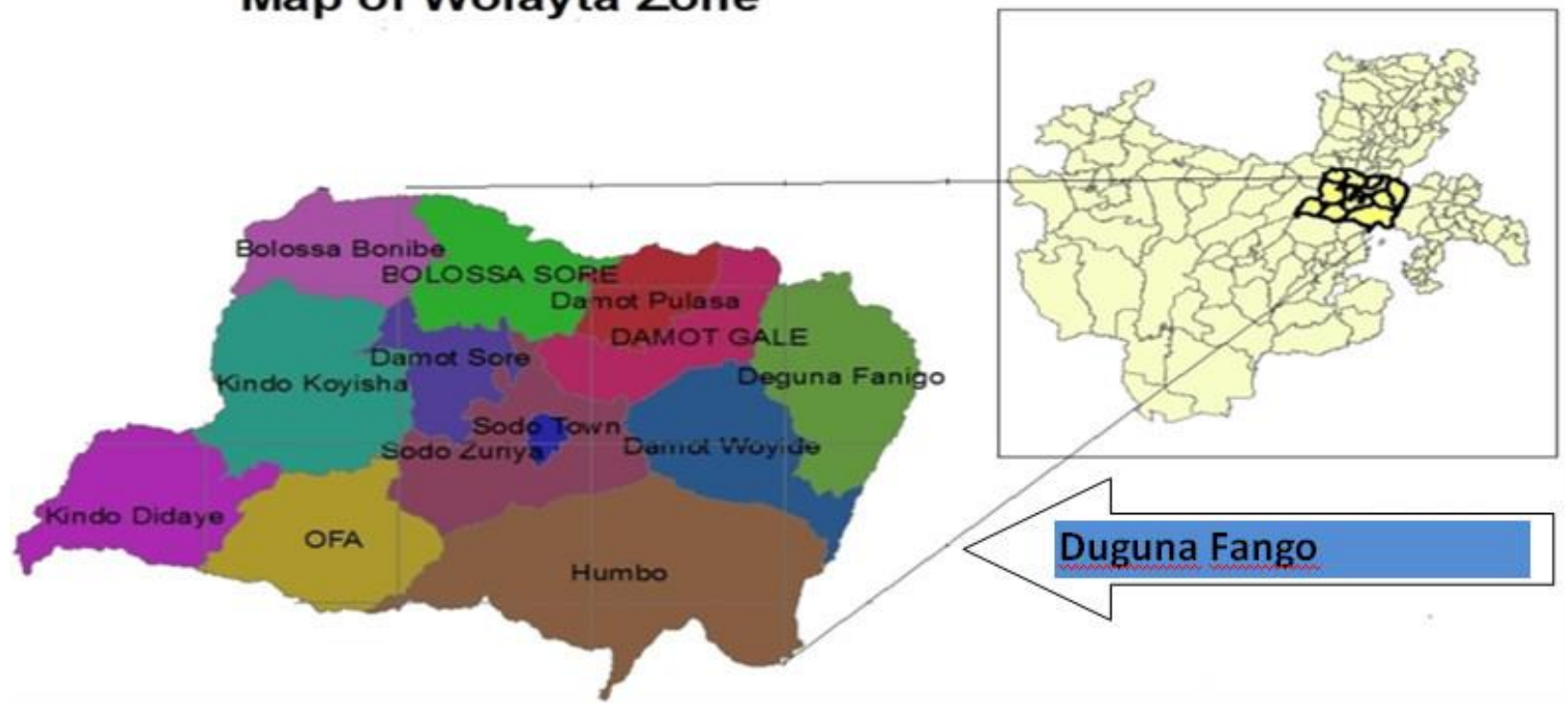

Figure 2: Mao showing the study

There are 6 health centers, 29 health posts and 8 different level clinics. According to Deguna Fango Woreda Finance and Economy report of 2013, the Woreda has a total population of 114,359 . Among them $49 \%$ male and $51 \%$ female. The Woreda has 26 rural and 2 urban Kebeles. The Woreda health facilities involve on different activities to minimizing unintended pregnancy like: FP services including long term (IUCD, implant, jedle) and short term (Depo, pills, condoms) with coverage of $30 \%$ and $80 \%$ respectively.

\section{Study design}

Quantitative research design and facility based cross sectional study method was instrumental for the current study at hand in Deguna Fango Woreda, Southern Ethiopia.

\section{Source population}

The source population comprised of all currently pregnant women who were attending at least in one of the health centers in Deguna Fango Woreda, Southern Ethiopia.

\section{Eligibility criteria}

Inclusion criteria:

Pregnant women

Exclusion criteria:

Woman who was sick or unwilling to participate

\section{Variables of the study}

Dependent variable:

Unintended Pregnancy

Independent Variables:

Socio-demographic variables: Age of women, ideal number of children, age of first marriage, women's education, husband's education, spousal communication, women's autonomy.

Access to health information variables: Radio/TV, travel time distance, health extension workers visit. Contraceptive related factors: Knowledge, attitude and use of contraceptive.

\section{Study population}

The study population was that currently pregnant woman in Deguna Fango wereda who visited health institution and selected as study population.

\section{Sample size}

Objective 1: The sample size was determined by using EPI-Info version 3.5.1 and single population proportion formula for cross sectional study. The equation using population proportion given by, $\mathrm{n}=\left(\mathrm{Z}_{\alpha / 2)^{2}} \mathrm{pq} / \mathrm{d}\right)$; Where $\mathrm{n}$ 
$=$ Sample size; $Z_{\alpha / 2)}=$ standard value corresponding to a $95 \%$ level of significance $=1.96 ; p=$ expected proportion of population practicing unintended pregnancy is $=34 \%=0.34$ Hosanna town, 2012 [25]; $q=(1-p)=(1-0.34)=0.66 ; d$ $=$ absolute precision $(5 \%)$. Therefore, from the above for $1^{\text {st }}$ specific objective sample size was:

$\mathrm{n}=(1.96)^{2} \times 0.34 * 0.66 / 0.05 \times 0.05$

$\mathrm{n}=0.862055 / 0.0025=345$

$10 \%$ of non response rate $=34$

$\mathrm{n}=345+10 \%$ of non response rate $=\mathrm{n}=345+34=379$ was the sample.

\section{Objective 2:}

A two proportion sample calculations equation using EPI - Info Version 3.5.1 was used to address the $2^{\text {nd }}$ specific objective. Considering mother education: $95 \% \mathrm{CI}$, power $80 \%$, ratio of $-1: 1$, the proportion of unintended pregnancy among illiterate mothers - $53.5 \%$, the proportion among non-exposed (literate) mothers 39.5\%, the calculated sample size with $10 \%$ contingency was $n=477$ (www.guttmacher.org, 2010).

Considering another factor, husband desire for family size, the proportion of un-intended pregnancy among exposed 57.3\%, and that among non-exposed $27.5 \%$; the sample size with $10 \%$ contingency was 108 (www.guttmacher.org, 2010).

Summary of sample size calculated by EPI - Info for associated factors using different assumption Sampling procedure

\begin{tabular}{|l|l|l|l|l|l|l|l|}
\hline Factors & $\begin{array}{c}\text { Proportion in } \\
\text { exposed }\end{array}$ & $\begin{array}{c}\text { Proportion in } \\
\text { un-exposed }\end{array}$ & $\begin{array}{l}\text { Odds } \\
\text { ratio }\end{array}$ & $\begin{array}{c}\text { Sig. } \\
\text { test }\end{array}$ & Power & $\begin{array}{c}\text { Ratio of } \\
\text { control to case }\end{array}$ & $\begin{array}{c}\text { Total sample } \\
\text { size }(10 \%)\end{array}$ \\
\hline $\begin{array}{l}\text { Uneducated } \\
\text { mother }\end{array}$ & $53.50 \%$ & $39.50 \%$ & 1.752 & $95 \%$ & $80 \%$ & $1: 01$ & 477 \\
\hline $\begin{array}{l}\text { Husband desire } \\
\text { for family size }\end{array}$ & $57.30 \%$ & $27.50 \%$ & 3.541 & $95 \%$ & $80 \%$ & $1: 01$ & 108 \\
\hline
\end{tabular}

The sample frame for this study was 1450 study population which was taken the previous registration from each health centers and it was developed from five health centers. Availability sampling was used to select five (Kaye, 2006) health centers from Deguna Fango, service delivery points out of six. Then after that systematic random sampling method was used to select the sample.Sample interval was determined by dividing the total study population to the sample size. $(\mathrm{N} / \mathrm{n}=1450 / 477=3)$. Every 3rd woman was selected once the first study subject was selected randomly.. These represent the different clinics that Deguna Fango Health office offers its services to unintended pregnancy and associated factors. The antenatal services including other services were providing at each of these service delivery points were essentially the same. Given the total average clinic attendance of 1450 clients for all service delivery points and that the estimated attendance for each service delivery point was: - Bitena Health Centre 285, Dimtu Health Center 405, Edo Health Center 244, Kercheche Health Center 244 and Anka Health Center 272 clients. The proportionate sample size calculated from previous attendances per service centre was; Bitena Health Center: $(285 / 1450) * 477=94$; Dimtu Health Center $=(405 / 1450) * 477=133$; Edo Health Center $=(244 / 1450) X^{*} 477=80$; Kercheche Health Center $=$ $(244 / 1450) * 477=80$; Anka Health Center $=(272 / 1450) * 477=9$.

Schematic Presentation: Under Deguna Fango Woreda Health Office, there are six health centers. In this study five health centers are included.

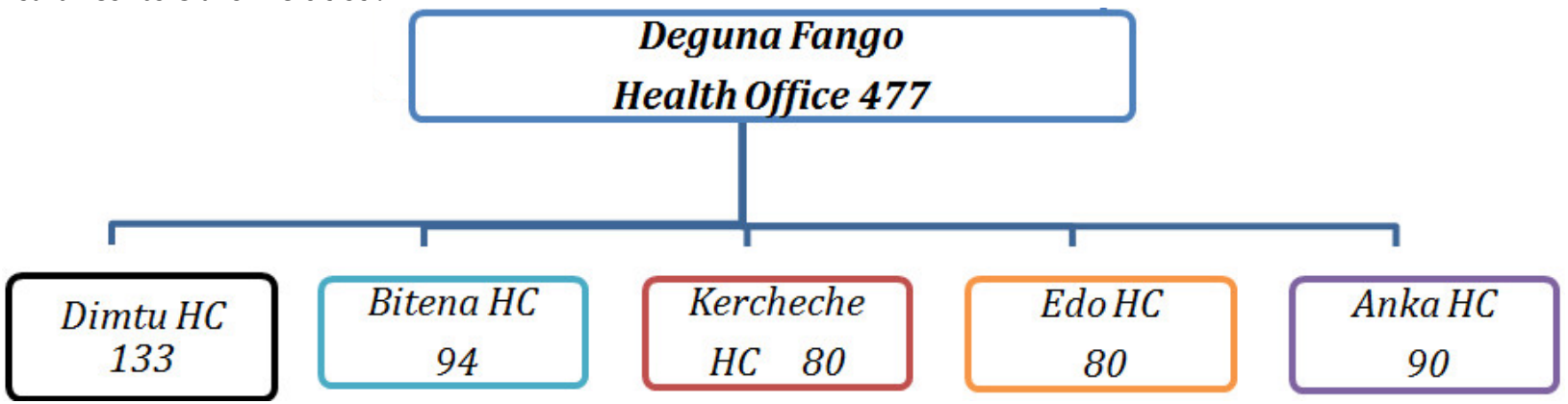

Fig. 3: Sampling Scheme

For the reason that $2^{\text {nd }}$ sample size 477 was greater number than assumption in the $1^{\text {st }}$ sample size of 379 . So the sample size of the study was 477 study participants. The expected sample size was 477 they were the actual number of persons were interviewed. Also the actual number of respondents was interviewed at each service centre as their minor variations. These may arise due to differences in actual attendances for that particular service. A proportional sample 
was drawn randomly from each of the five (Kaye, 2006) strata using previous attendance data obtained from respective clinics of the last visits. At every clinic all clients that come for antenatal services were registered as they arrive and they are given arrival numbers to foster the process of first come first serve. It was from these numbers that every $3^{\text {rd }}$ person as they registered was included in the sample at each clinic until the required number of respondents' was attained as calculated above. If the $3^{\text {rd }}$ person did not meet the criteria the next person was considered.

\section{Data collection procedure}

Data was collected through pre-tested structured questionnaire, which was developed after reviewing different literature. The questionnaire was first prepared in English then translated to Amharic by language expert and $5 \%$ of the questionnaire was pre- tested in neighbor Woreda. The questionnaire was assessed for its clarity, completeness and its relevance. Some difficult questions to ask were rephrased, and some unnecessary questions and skip patterns were corrected. While some ideas necessary were added.

Women who were currently pregnant during the survey were the main participants of the study, and all pregnancies regardless of the outcomes were considered in the study. Women who were currently pregnant at the time of the interview formed the sample size for analysis respondents were asked about their sociodemographic background, their children, their knowledge and use of contraceptives, their children's health, reproductive health, and other information as well. From these respondents, women whose pregnancies were mistimed or unwanted were identified. These women were asked the planning status of the current pregnancy; whether the pregnancy was mistimed, unwanted or they bear according to their plan.

\section{Data collection instrument}

Data was collected using a pre-tested, structured and interviewer guided questionnaire adopted from EDHS 2011 and related studies. The questionnaire adopted was modified and contextualized to the local situation and the research objectives. The questionnaire was prepared first in English then translated in to Amharic, and back to English by language experts to check for consistency. Study participants were interviewed in Amharic language.

\section{Data collector training and pre-testing}

Five nurses were identified for data collection ( 3 were females). They were trained for two days by the principal investigator on the study instrument, consent form, how to interview and data collection procedure. One midwife trained nurse was assigned as supervisor for observation data in each health center. Before the actual data collection, the questionnaire was pre-tested on a similar health center which was not included in the study. The supervisor has checked the day to day activity of data collectors for all the questionnaires were filled for completion, clarity and proper identification of the respondents. Then the principal investigator randomly checked on average about $10 \%$ of the supervisors' work every day. Incomplete and unclear questionnaires were given back to the interviewer to get completed data. The purpose of the pre-testing was to ensure that whether respondents were able to understand the questions or not and to check the wording, logic and skip patterns of the questions in a rational way to the respondents. Amendments were made accordingly after the pre-testing.

\section{Data quality assurance}

To keep data quality the observation check list was prepared in English whereas for the respondents questionnaire was prepared in English and translated into Amharic. The guide line was assigned. Data collectors and supervisors were given training for two days on how to use the questionnaire on interviewing and on observation techniques, privacy, discipline and approach to respondents. A pre-test was carried out by data collectors on health centers and after pre-testing, comments was included in the questionnaire and experiences were obtained on how to proceed in the final data quality control.

A data collection instrument's reliability is defined as the consistency with which it measures the target attribute and/or concerns a measure's accuracy. In order to ensure reliability of the instrument in this study a pre-test was conducted. This involved testing the actual tool on a small sample taken from the general population. A week before execution of the study, the actual questionnaire was administered to 25 women of reproductive age (15-49) group who were currently pregnant were asked in neighbor Damot Gale woreda health center in order to ensure that the tool would collect the desired data and that the questions were clear. After analyzing data from the pre-test, questions which were not clear were rephrased to ensure that appropriate responses would be obtained in the future.

Validity of an instrument concerns the extent to which the research measures what it imply to measure without bias or distortion. To test the instrument, a copy of the questionnaire was submitted to the study supervisor to examine whether the number and type of items in the questionnaire measured the concept or construct of interest. Questions in the tool were developed based on findings from previous studies and the literature reviewed and in order to reduce error data collectors were trained and the collected data were cheeked for correctness. 


\section{Data management}

Data collected from the field was handled properly by researcher and counted and reviewed every day. Every day night the supervisor/researcher was clear ambiguity, missed data, wrongly filed and coded data and conducted one hour discussion session before beginning the next day data collection. All raw data collected from the health center were filed in hard copy and documented in soft copy. For the quantitative data, the data was entered by using Open EPI software version 3.5.1 after checking for completeness, coded, cleaned for inconsistencies and missing values and for normality of distributions; SPSS version 16.0 was used for analysis

\section{Data analysis}

Descriptive statistics was computed to determine the level of unintended pregnancy and associated factors. Bivariate analysis was carried out between the outcome and predictor variables. Multivariate logistic regression analysis was used to identify the associated factors. The strength of association was measured by adjusted odds ratio with $95 \%$ confidence intervals. Statistical significance was declared at $\mathrm{p}<0.05$. Logistic regression analysis was used to examine the odds of unintended pregnancy for each of the risk factors controlling for the others in the logistic regression model, the selected seven independent variables were identified as factors potentially associated with unintended pregnancies.

\section{Ethical considerations}

Ethical clearance was obtained from the ethical review committee of Wolaita Sodo University and permission to conduct the study was obtained from District woreda heath office. Deguna Fango district health office was written letters to their respective health centers. Informed verbal consent was obtained from each participant prior to inclusion to study and then respondents were included in the study on voluntary bases and after they have given verbal consents. All records were coded and accessed by the researcher only to assure confidentiality. Names of respondent were recorded anonymously during data processing and analysis. Respondents were interviewed in a private place to ensure comfort and privacy. Respondents had an absolute right to refuse participation in this research and respondents' are not obliged to answer any question that they do not want to answer the right and willingness of respondents' was respected.

\section{RESULTS}

Socio-Demographic information: Four hundred seventy seven pregnant women were identified to participate in the study. Out of these, four hundred seventy (470) currently pregnant women were interviewed with the response rate of $98.5 \%$. The rest were not visited health center up-to the final date of data collection process.

With regard to the age of respondents' to which age was ranged from 15 to 49 years, the majority (45.3\%) were in the age categories of 25 to 29 , and the least category of the respondents was found in the age of 40 and above. Concerning age at first marriage depicted that 259 (55.1\%) of respondents married at age group 15 to 19 . This indicated that the majority of respondents found to be at the productive age.

In terms of level of education, $323(68.7 \%)$ were unable to read\& write, $100(21.3 \%)$ were primary school completed, and $47(10 \%)$ secondary and above educational level. It revealed that how religion and level of education influenced the use of contraceptive method to avoid unintended pregnancies.

Regarding ethnicity of respondents, it shows that, $466(99.1 \%)$ were Wolaita. With regards to marriage status of the respondent, the result depicted that, 451 (96\%) was married/in union and 19 (4\%) were widowed/ divorced / separated.

With regard to occupation, 418 (88.9\%) house hold and unemployed, 23 (4.9\%) of respondents were government employee, 7 (1.5\%) were private employee, 22 (4.7\%) were do other occupational activities. When considering husband's educational status, 259 (55.1\%) were unable to read and write, 107 (22.8 \%) were primary school, and 104 $(22.1 \%)$ were secondary and above educational level. This infers that even the husbands needs special attention to aware the appropriate use of contraceptive method to limit the number of children.

Table 1: Socio demographic characteristics of currently pregnant woman, Deguna - 2014

\begin{tabular}{llll}
\hline Items & Character & Frequency $(n=470)$ & $\%$ \\
\hline Age of respondent & $15-19$ & 32 & 6.8 \\
& $20-24$ & 69 & 14.7 \\
& $25-29$ & 213 & 45.3 \\
& $30-34$ & 117 & 24.9 \\
& $35-39$ & 32 & 6.8 \\
& $40-44$ & 7 & 1.5 \\
\hline
\end{tabular}




\begin{tabular}{|c|c|c|c|}
\hline \multirow[t]{4}{*}{ Age at first marriage } & $10-14$ & 13 & 2.8 \\
\hline & $15-19$ & 259 & 55 \\
\hline & $20-24$ & 186 & 39.6 \\
\hline & 25 and Above & 12 & 2.6 \\
\hline \multirow[t]{3}{*}{ Highest grade completed } & Illiterate/read\& write & 323 & 68.7 \\
\hline & Primary & 100 & 21.3 \\
\hline & Secondary and above & 47 & 10.0 \\
\hline \multirow[t]{2}{*}{ Ethnicity } & Wolaita & 466 & 99.1 \\
\hline & Others & 4 & .9 \\
\hline \multirow[t]{4}{*}{ Occupation } & House wife & 418 & 88.9 \\
\hline & Government employee & 23 & 4.9 \\
\hline & Private employee & 7 & 1.5 \\
\hline & Others & 22 & 4.7 \\
\hline \multirow[t]{2}{*}{ Marital status } & Married/In union & 451 & 96 \\
\hline & Widowed/divorced / separated & 19 & 4 \\
\hline \multirow[t]{4}{*}{ Husband's occupation } & Farmer & 353 & 75.1 \\
\hline & Government employee & 43 & 9.1 \\
\hline & Private employee & 48 & 10.2 \\
\hline & Others & 26 & 5.5 \\
\hline \multirow{3}{*}{$\begin{array}{l}\text { Husband's } \\
\text { completed }\end{array}$} & Illiterate/read\& write & 259 & 55.1 \\
\hline & Primary & 107 & 22.8 \\
\hline & Secondary and above & 104 & 22.1 \\
\hline
\end{tabular}

With regard to occupation of male, the result reveals that, majority of respondents' husbands which account for 353 $(75.1 \%)$ were farmers, 43 (9.1\%) government employee, $48(10.2 \%)$ private employee and 26 (5.5\%) work on other activities. When comparing the educational status of both, husbands are more educated (44.9\%) than women $(31.3 \%)$. Most of respondents were house hold and unemployed; this in turn affects their income and economic status to improve their perception (Table 1).

Table 2: Frequency, Percentage, of Significant Variables of Religion, Income and Ways women to be exposed for unintended pregnancy $\mathrm{N}=470$

\begin{tabular}{|c|c|c|}
\hline Significant Variable Items & Frequency & Percentage \\
\hline \multicolumn{3}{|l|}{ 1. Religion } \\
\hline Protestant & 361 & 76.8 \\
\hline Orthodox & 83 & 17.7 \\
\hline Muslim & 4 & 0.9 \\
\hline Others & 22 & 4.7 \\
\hline \multicolumn{3}{|l|}{ 2. Income } \\
\hline$<500$ & 200 & 42.6 \\
\hline $500-100$ & 180 & 38.3 \\
\hline$>1000$ & 90 & 19.1 \\
\hline \multicolumn{3}{|c|}{ 3. What exposed to you to unintended pregnancy } \\
\hline Lack of contraceptive & 33 & 7.2 \\
\hline Misuse of contraceptive & 62 & 13.2 \\
\hline Husband Influences & 66 & 14 \\
\hline Others & 309 & 65.7 \\
\hline
\end{tabular}

As shown in the above table 2, item one reveal that a large majority 361 (76.8\%) of the respondents belong to protestant religion. It would therefore, be possible to infer that our realization the fact the respondents are least or practically never involved in use of contraceptive mechanism to control unintended pregnancy because of religion influence and thus, is considered as major challenges to family planning. The idea behind table 2 item two is to find out the income level of the respondents to compare their family size. Accordingly, nearly half of the respondents claimed that their monthly income were less than 500 with frequency value of 200 (42.6\%). Meanwhile, with frequency of 180 (38.3\%) of the respondents remarked that their monthly income were found in between 500-1000. I can infer that their monthly income is not proportional to their family size and sufficiently handle their kids. The third significant variable is ways women to be exposed for unintended pregnancy. Consequently, with the Page 18

Malaysian Jaurnal of Medical and Biological Research • Volume 3, No I/20I6 
calculated values of frequency $309(65.7 \%)$ depicted that there are other mechanism that exposed women to unintended pregnancy other than lack of contraceptive methods, misuse of contraceptive and husband influences. But husband influences with frequency values of $66(14 \%)$ dominated other remaining mechanisms like lack of contraceptive and misuse of contraceptive with frequency values of $62(13.4 \%)$ and $33(7.2 \%)$ respectively.

Table 3: Frequency, Percentage of Significant Variables of Society view, ideal number of children, children ever born $\mathrm{N}=470$

\begin{tabular}{|c|c|c|}
\hline Significant Variable Items & Frequency & Percentage \\
\hline \multicolumn{3}{|l|}{ 4. Ideal Number of Children } \\
\hline $1-3$ & 69 & 14.7 \\
\hline $4-6$ & 349 & 74.3 \\
\hline 7 and above & 52 & \\
\hline \multicolumn{3}{|l|}{ 5. How many children do you have been } \\
\hline 0 & 109 & 23.2 \\
\hline $1-2$ & 99 & 21.4 \\
\hline $3-4$ & 176 & 37.4 \\
\hline 5 and above & 86 & 18.3 \\
\hline
\end{tabular}

As it was indicated in the above table 3 item one, despite the fact that a considerable proportion 201 (42.8\%) of the respondents responded as positively, as high as $269(57.2 \%)$ of the respondents ascertained that the society do not encouraging unintended pregnancy. It seemed therefore, even if they lacks continues awareness creation, safer to suggest that the society are not going to support unintended pregnancy. As observed in table 3 item two, which is entitled as "ideal number of the children" the majority of the respondents as the calculated frequency values and percentage $349(74.3 \%)$, revealed that the ideal number of the children were in between $4-6$. But respondents with their calculated frequency values and percent of 69 (14.7 \%) claimed that the ideal number of the children were 1-3. So it is possible to conclude that the society can see the number of children as an asset to their future careers. With regard to children ever born, it could be noted in item three of the same table that with the frequency values of 176 $(37.4 \%)$ of the respondents claimed that the number of children ranged in between 3- 4. It would therefore, be generalize that the practice of using contraceptive mechanisms was lacking in a more of complete basis for rational decisions of the determination of number of children per house hold as compared with their monthly income of the respondents.

Table 4: Frequency, Percentage of Significant Variables of Planning Experience, Self -feeling, and Relationship of unplanned pregnant women, $\mathrm{N}=470$

\begin{tabular}{ccc}
\hline Significant Variable Items & Frequency & Percentage \\
\hline 6. Do they plan? & & \\
Yes & 254 & 54.0 \\
No & 216 & 46.0 \\
I Don't know & 0 & \\
7. Does Unplanned pregnancy makes you feel good about yourself. & \\
Yes & 425 & 90.4 \\
No & 45 & 9.6 \\
Don't know & 0 & - \\
8. Does unplanned pregnancy strengthen your relationship & \\
Yes & 434 & 92.3 \\
No & 36 & 7.7 \\
\hline
\end{tabular}

In view of planning practice of being pregnant or not, the above table clearly described either the respondents planned to have proportional family size or not. Accordingly, more than half of respondents as calculated frequency, percentage, , $254(54 \%)$,) remarked that they used planning to give birth or being pregnant to have children but near to half of the respondents with calculated frequency, percentage, of $216(46 \%)$, claimed that there is no planning practice for being pregnant or not. It is therefore well recognized that a considerable emphasis has to be placed on effective planning practice in order to prevent unintended pregnancy of women in the study areas. On the same table item two with regard to the issue of feeling good because of unintended pregnancy, the respondents all in all with calculated frequency, percentage of $425(90.4 \%)$, ) portrayed that they feel good after despite it is unintended pregnancy because they always believe that the children are the gift of God and as an asset of the society. On the other hand, in the same table item three depicted about the relationship of women and their husband after unplanned pregnancy. The results as a calculated frequency and percentage, of $434(92.3 \%)$, revealed that 
unintended pregnancy do not create any negative consequence rather it strengthen their relationship with their husbands and they are also happy on it as obtained from the finding.

\section{Magnitude of unintended pregnancy}

The intensions of the respondents' about their pregnancy less than one- tenth of the respondents mentioned that they wanted their current pregnancies later which was mistimed $=37(7.9 \%)$ and the other approximately one fourth of the women reported that they did not want their current pregnancies at all (unwanted $=135(28.7 \%)$. When summing up these two, more than three-tenth of respondents which account for $172(36.6 \%)$ reported their current pregnancies were unintended (that is mistimed and unwanted pregnancy) (Table 5).

Table 5: Distribution of respondents' by reported unintended pregnancy in Duguna Fango Woreda

\begin{tabular}{|c|c|c|}
\hline Pregnancy out comes & Frequency & $\%$ \\
\hline Unintended & 172 & 36.6 \\
\hline Mistimed & 37 & 7.9 \\
\hline Unwanted & 135 & 28.7 \\
\hline Planned & 298 & 63.4 \\
\hline Total & 470 & 100 \\
\hline
\end{tabular}

Access to health information refers to information source about unintended pregnancy and associated factors which women received information from radio, television, visited by health workers, formal and informal health education class in school, family and other. Accordingly, the finding of the current study depicted that, 452 (96\%) of respondents has exposure to mass media and $18(14 \%)$ of respondents have no exposure to mass media. According to travel time distance, the result reveal that, majority of respondents which account for $382(81 \%)$ are mentioned they travel 30-60 minutes to gate FP services and 76 (1.6 \%) of interviewers are reported they travel less than 30 minutes to FP services. Meanwhile, the number of respondents visited by health extension workers were 298 (63.4 $\%)$ and $172(36.6 \%)$ of respondents not visited by health extension workers.

With regards to contraceptive related factors; the study participants responded that, they have knowledge of at least two methods of contraceptive use, two risk factors of unintended pregnancy, two risk factors of unintended pregnancy for women, two risk factors of unintended pregnancy for infants with calculated values of $202(43 \%), 399$ (85\%), $194(41 \%), 267(57 \%)$ respectively from five alternative knowledge chaises (Table 6).

Table 6: Contraceptive knowledge of currently pregnant woman, Deguna Fango, 2014

\begin{tabular}{|l|c|c|c|}
\hline Name of variables & Character & Frequency & $\%$ \\
\hline Knowledge of at least two methods of contraceptive use & Yes & 202 & 43 \\
\cline { 2 - 4 } & No & 268 & 57 \\
\hline Knowledge of at least two risk factors of unintended pregnancy & Yes & 399 & 85 \\
\cline { 2 - 4 } & No & 71 & 15 \\
\hline Knowledge of at least two risk factors of unintended pregnancy for women & Yes & 194 & 41 \\
\cline { 2 - 4 } & No & 276 & 59 \\
\hline Knowledge of at least two risk factors of unintended pregnancy for infants & Yes & 267 & 57 \\
\cline { 2 - 4 } & No & 203 & 43 \\
\hline Over all knowledge of candidate & Yes & 266 & 57 \\
\cline { 2 - 4 } & No & 204 & 43 \\
\hline
\end{tabular}

Factors associated with unintended pregnancy

The statistical significance of this study is expressed as $p$-value (probability value). It is customary to say the effect is significant if the $p$-value is less than or equal to 0.05 . This means that the probability that the effect is the result of chance is less than $5 \%$ or researcher is $95 \%$ confident that the difference is due to the treatment effect. P-value $<0.01$ indicates highly significant difference among treatments to the confidence level of $99 \%$. Accordingly, the researcher selected the significant variables only to which their $P$ - value ranged as stated above and rejected the other variables which is insignificant to which affect unintended pregnancy and their P-value is greater than 0.05. Additionally, through bivariate analysis crude odd ratio (COR) and by multivariate analysis adjusted odd ratio (AOR) clearly described on table 7.

Hence, the women who having husband desire for family size, income of the women in the house hold, societies encourage unintended pregnancy, number of children born, planning experience of women, religion, self feeling of pregnant women, and the ways women exposed to unintended pregnancy were selected as candidate variables with $\mathrm{p}<0.05$ in bivariate analysis for multivariate logistic regression. 
The current study at hand portrayed that, unintended pregnancy are strongly associated with the women who having husband desire for family size was a major factor, a women who having husband desire for family size were 3 times higher possibility to the risk of unintended pregnancy rather than the women who have no husband desire for family size $(\mathrm{COR}=2.319,95 \% \mathrm{CI}(1.167-4.607)$ with its p-value of 0.016 and $(\mathrm{AOR}=3.082,95 \% \mathrm{CI}(1.218-7.798)$ and its p-value is 0.017 .

There was also association between societies encourage pregnancy and the risk of unintended pregnancy women who have societies encourage pregnancy are reported they have practicing 0.4 fold higher number of unintended pregnancy than the women who have no societies encourage pregnancy with calculated (COR $=0.447,95 \% \mathrm{CI}$ (0.305- 0.656) with its p-value of 0.000 and (AOR $=0.416,95 \%$ CI 0.230-0.750) its p-value 0.004 .

There was statistical significant association between number of children for currently pregnant women with the unintended pregnancy, those respondents having no child were 3 times additional to be unintended pregnant than those women with 1-2, 3-4,5 and more children calculated (COR $=3.054,95 \%$ CI 1.597-5.840) p-value of 0.01 and $(\mathrm{AOR}=3.128,95 \% \mathrm{CI}(1.086-9.014)$ its p-value 0.035 .

The other item in the same table is monthly income of the respondents. The calculated values of $(\mathrm{COR}=2.382,95 \%$ CI 1.429-3.972) $\mathrm{p}$-value of 0.001 and $\mathrm{AOR}=2.39495 \% \mathrm{CI}(1.196-4.793)$ revealed that there is strong relationship between unintended pregnancy and their monthly income and their monthly income is less than 500 is equivalent to that of in between $500-1000$ at significant level of p-value of 0.014 . With the same token, religion is the most significant variable of the current study at hand. Accordingly, there was significant association between religion and unintended pregnancy to which those respondents who belong to protestant were 4 times higher with the unintended pregnancy than those who belong to Orthodox with calculated value of (COR=6.042 $95 \%$ CI 2.17916.715) $\mathrm{P}$ value of 0.001 and $(\mathrm{AOR}=4.860,95 \% \mathrm{CI},(1.338-17.660)$ at significant level of $\mathrm{p}=0.016$.

Table 7: Bivariate and Multivariate Analysis for Association of Unintended pregnancy and selected explanatory variables, Deguna Fango Woreda, 2014

\begin{tabular}{|c|c|c|c|c|}
\hline \multirow[t]{2}{*}{ Variables } & \multicolumn{2}{|c|}{ Pregnancy out come } & \multirow[b]{2}{*}{ Crude OR $(95 \% \mathrm{CI})$} & \multirow[b]{2}{*}{ Adjusted OR (95\% CI) } \\
\hline & $\begin{array}{l}\text { Unintended } \\
(\%)\end{array}$ & $\begin{array}{c}\text { Intended } \\
(\%)\end{array}$ & & \\
\hline \multicolumn{5}{|l|}{ Husband desire for family size } \\
\hline Yes & $20(55.6)$ & $16(44.4)$ & $2.319(1.167-4.607)^{* *}$ & $3.082(1.218-7.798)^{*}$ \\
\hline No & $152(35)$ & $282(65)$ & 1.0 & 1.0 \\
\hline \multicolumn{5}{|c|}{ Societies encourage unintended pregnancy } \\
\hline Yes & $106(52.7)$ & $95(47.3)$ & $.447(.305-.656)^{*}$ & $0.416(0.230-0.750)^{* *}$ \\
\hline No & $192(71.4)$ & $77(28.6)$ & 1.0 & 1.0 \\
\hline \multicolumn{5}{|l|}{ Number of children born } \\
\hline 0 & $89(81.7)$ & $20(18.3)$ & $3.054(1.597-5.840)^{*}$ & $3.128(1.086-9.014)^{*}$ \\
\hline $1-2$ & $49(49.5)$ & $50(50.5)$ & $0.673(.375-1.205)$ & \\
\hline $3-4$ & $109(61.9)$ & $67(38.1)$ & $1.116(.659-1.891)$ & \\
\hline 5 and more & $51(59.3)$ & $35(40.7)$ & 1.0 & 1.0 \\
\hline \multicolumn{5}{|l|}{ Income } \\
\hline$<500$ & $139(69.5)$ & $61(30.5)$ & $2.382(1.429-3.972)^{*}$ & $2.394(1.196-4.793)^{*}$ \\
\hline $500-1000$ & $115(63.9)$ & $65(36.1)$ & $1.850(1 / 107-3.090)$ & $1.663(0.830-3.332)$ \\
\hline$>1000+$ & $44(48.9)$ & $46(51.1)$ & 1.0 & 1.0 \\
\hline \multicolumn{5}{|l|}{ Religion } \\
\hline Protestant & $130(36)$ & $231(64)$ & $6.042(2.179-16.755)^{*}$ & $4.860(1.338-17.660)^{*}$ \\
\hline Orthodox & $25(30.1)$ & $58(69.9)$ & $7.888(2.621-23.742)$ & $5.277(1.344-20.713)$ \\
\hline Others & $17(65.4)$ & $9(34.6)$ & 1.0 & 1.0 \\
\hline \multicolumn{5}{|c|}{ Self-feeling of unintended pregnant women } \\
\hline Yes & $9(20)$ & $36(80)$ & $.402(.189-.856)^{+4}$ & $.284(0.105-0.764)^{*}$ \\
\hline No & $163(38.4)$ & $262(61.6)$ & 1.0 & 1.0 \\
\hline \multicolumn{5}{|c|}{ What exposed to you to unintended pregnancy } \\
\hline Lack of contraceptive & $18(54.5)$ & $15(45.5)$ & $0.281(0.135-0.585)$ & 1.0 \\
\hline Misuse of contraceptive & $46(74.2)$ & $16(25.8)$ & $0.117(0.063-0.219)$ & 1.0 \\
\hline Husband Influences & $30(45.5)$ & $36(54.5)$ & $0.405(0.234-0.701)^{*}$ & $0.248(0.092-0.667)^{4 *}$ \\
\hline $\begin{array}{l}\text { Others } \\
\text { Pther }\end{array}$ & $78(25.2)$ & $231(74.8)$ & 1.0 & 1.0 \\
\hline $\begin{array}{l}\text { Planning experience of women } \\
\text { Yes }\end{array}$ & $148(58.3)$ & $106(41.7)$ & $0.614(0.419-0.900)^{*}$ & $0.357(0.184-0.692)^{* *}$ \\
\hline No & $150(69)$ & $66(30.6)$ & 1.0 & 1.0 \\
\hline
\end{tabular}

Note: * Variables significant at $\mathrm{p}<0.05,{ }^{* *}$ Variables significant at $\mathrm{p}<0.01$ in both COR and AOR 
There is also significant relationship between self-feeling of pregnant women and unintended pregnancy. Consequently, respondents with positive feeling were 0.2 times higher with unplanned pregnancy than that of negative feeling with calculated of value (COR= $0.402,95 \% \mathrm{CI} 0.189-0.856) \mathrm{p}$-vale of 0.018 and $(\mathrm{AOR}=0.284,95 \% \mathrm{CI}$ (0.105-0.764) at significant level of $\mathrm{p}=0.013$.

The other significant variable in the current study at hand is planning experiences of the respondent to pregnancy. Accordingly, the calculated value of $(\mathrm{COR}=0.641,95 \%$ CI $0.419-0.900) \mathrm{p}$-value of 0.012 and (AOR=0.357, $95 \% \mathrm{CI}$, $(0.184-0.692)$ at the significant level of $p=0.002$ revealed that there was strong relationship between unintended pregnancy and planning experience of respondents.

Ways women exposed to unintended pregnancy is the other significant variable under this study and has statistical relationship with unintended pregnancy. Accordingly, the calculated value of (COR=0.405, $95 \%$ of CI 0.234-0.701) p-value of 0.001 and (AOR=0.248, $95 \%$ CI 0.092-0.667) p-value of 0.006.

\section{Discussion}

In this study, an attempt was made to determine the level of unintended pregnancy and associated factors based on a representative sample of 477 women drawn by systematic random sampling from five health centers from Duguna Fango Woreda, South Ethiopia.

The finding of the research depicts that, there is no single factor accounted for the high rates of unintended pregnancy; rather many factors were interwoven to affect the occurrence of the event. Among these sociodemographic and service related factors, documented in this study were income of the women, husband desire for family size, societies encourage unintended pregnancy, number of children born, planning experience of women, religion, the ways women exposed to unintended pregnancy and self-feeling of pregnant women are significant predictors of unintended pregnancy in Deguna Fango Woreda, Southern Ethiopia.

More than 172 respondents (36.6\%) reported their current pregnancies were unintended (that is, mistimed and unwanted pregnancy). This figure is comparable with national average which is $35 \%$ according to EDHS, 2011. In addition this result is less than the study done in a district, southern Ethiopia that is $42.4 \%$ (Regassa and Kebede, 2011). The difference could be attributed to the progress in the awareness and availability of services, study design difference and other factors related to the study areas.

The husband desire for family size was the main reason for the increment of unintended pregnancy level in the study area which is reported by the respondents the odds of unintended pregnancy is 3 times higher in women whose husband desire for family size than the women whose husband has no desire for family size this finding matches with the study done in Damot Gale (Regassa and Kebede, 2011).

The risk of experiencing unintended pregnancy is higher in women who are unable to read and write. Even little advance in education improves women's decision making power and leading to avoidance of unintended pregnancy, hence, education has a pervasive impacts on a women's pregnancy intention since it empowers women to manage their family size and intensively develop self-feeling and their planning experiences reduces the chance of unintended pregnancy with the same study conducted in Hawassa, southern Ethiopia, showed the same results (Akale, 2008).

According to this study the women's number of children born is associated with unintended pregnancy (Rashid and Shifa, 2007), this article confirmed that the likelihood of unintended pregnancy was higher among women who had higher number of living children and the current analysis also found that women who have no child experienced 3 times more unintended pregnant than women who have children. Similarly, society encourage for unintended pregnancy plays an important role in increasing the risk of unintended pregnancy women have no encouragement in being unintended pregnant in the society had 0.4 times reduced odds of unintended pregnancy which coincide with other studies (Akale, 2008). The reasons given by respondents, suggesting that feeling good in unintended pregnancy and good planning practices have pivotal role in the occurrence of events of unintended pregnancy. The predictor variables selected in the study area are related to either the women's characteristics or households' socioeconomic status or service related characteristics.

The result of the current study at hand reveal that, the planning experience of women was one of the major factors which affects unintended pregnancy, than women who had no experience on planning their pregnancy status in previous number of children born were discouraged from using modern contraceptives due to the information they get from the society. Also, they have fear and not initiative to use it and this coincide with other study (Akale, 2008). According to respondents' they had heard about the side effect of modern contraceptives (pills, injectables,) like gaining unwanted weight, skin rash, median (black spot on the face) and sterility.

The finding also portray that the women's self-feeling and ways women exposed to unintended pregnancy is the predictor variables for practicing unintended pregnancy the women who lacks positive self-feeling about unintended pregnancy were 0.2 times higher tendency to practice unintended pregnancy than the women who have negative self-feeling about the unintended pregnancy. 
There was also the significant association between income and unplanned/unwanted pregnancy. The respondents' who have higher income are 2 times chance to make the preventive decision about their pregnancy intention than the respondents' who have lower income in their house hold, occupational status of women has also a great role to improve their perception, empowerment, economic status this matches with other studies (Rashid and Shifa, 2007). The most frequent reason mentioned by the participants is that, they lack appropriate information, education and communication on preventing unplanned/unwanted pregnancy. According to this finding empowerment is also important to overcome different risk factors which disable women to make the decision about their pregnancy intentions.

Empowerment in different perspectives like; educational, health education, and economic empowerment can reduce the severity of problems which expose the women for unintended pregnancy (Georges, 2012). It is necessary to improve knowledge about contraceptive uses among pregnant women.

\section{CONCLUSION AND RECOMMENDATIONS}

\section{Conclusion}

According to the study findings level of unintended pregnancy was found to be high $(36.6 \%)$ and it was a major reproductive health problem in the study area for family planning and thus deserves priority attention. The study concludes that no single factor accounted for the high rates of unintended pregnancy; rather many factors were interwoven to affect the occurrence of the event. Among these socio-demographic and service related factors, documented in this study shows that income of the women, husband desire for family size, societies encourage unintended pregnancy, number of children born, planning experience of women, religion, self feeling, ways women exposed to unintended pregnancy are significant predictors of unintended pregnancy in Deguna Fango Woreda, Southern Ethiopia.

\section{Recommendations}

Based on the findings and conclusion drawn from the study, the following recommendations were forwarded:

- Ministry of health in partnership with other implementing partners, should focus on their strategies to the family planning program, addressing the need of women on reproductive health issues.

- Different partners in partnership with the government should address the issue of un employment among women to improve their perception, empowerment and economic status, hence for them to be able to take care of themselves as well as their children.

- It is highly recommendable to conduct a qualitative study in the community and house hold in order to have an in depth discussion with regard to unintended pregnancies and associated factors in order to compliment the findings from this study.

- One of the major challenges to practice the contraceptive method is the level education of the respondents and their husbands. The majority of the respondents and their husbands are unable to read and write. Hence, the health center should facilitate continuous awareness creation program for local community on the practice of the appropriate contraceptive methods to reduce the challenges.

\section{REFERENCES}

Akale B. Determinants and Magnitude of Unintended Pregnancy. Hawassa town, SNNPR: AAU, 2008.

Alan Guttmacher Institute. Unwanted Pregnancy and Induced Abortion in Nigeria; Causes and Consequence. New York, 2006.

Bongaarts J, Sinding S. Population Policy in Transition in the Developing World Science. 2011, 333:6042, pp. 574-575.

Central Statistical Agency of Nigeria. Household characteristics and unintended pregnancy. Nigeria: Nigeria Demographic and Health Survey, 2008.

Central Statistical Agency. ICF International: Ethiopian Demographic and Health Survey. Addis Ababa, Ethiopia. Calverton, Maryland, USA; 2011.

Ciment J. Most Deaths Related to Abortion Occur in the Developing World. British Medical Journal. 1999, 318:7197, pp. 1509.

Eisenhart M. Conceptual frameworks for research circa: Ideas from a cultural anthropologist; implications for mathematics education researchers. Proceedings of the 13th annual meeting of the North American Chapter of the International Group for the Psychology of Mathematics Education Blacksburg, VA. 1991. vol. 1, pp. $202-219$.

Fantahun M, Chala F, Loha H. Knowledge, Attitude and Practice of Family Planning Among Senior High School Students in North Gondar. Ethiopian Med. J. 1995; 33(Central Statistical Agency of Nigeria, 2008):21-29.

Federal Democratic Republic of Ethiopia. Health and Health Related Indicators. 2004.

Georges N. Master Thesis on Causes of unintended pregnancy among adolescents in Addis Abeba, Ethiopia Submitted in partial fulfillment of the requirement for the Master's degree program in Public Health (MPH) Norwegian University of Life sciences (UMB) Department of Plant and Environment al Sciences May 2012

Gessessew A, Abortion and Unwanted Pregnancy in Adigrat Zonal Hospital, Tigray, North Ethiopia Mekele Hospital, P.O. Box 22, Mekele, Tigray, Ethiopia. African Journal of Reproductive Health Sept. 2010 (Regular Issue); 14(United Nations, 2008 ): 183 *for correspondence: Amanuel Gessessew. E mail: kalkidus@yahoo.com. 
Gipson JD, Koenig MA, Hindin MJ. The Effects of Unintended Pregnancy on Infant, Child, \& Parental Health: A Review of the Literature, Studies in Family Planning. 2008, 39:1, pp. 18-38.

Kabir SM. Causes and Consequence of Unwanted Pregnancy from Asian Women's Perspective. Intl. J. Obstet. 1989; 3(Supp):9-14. Kaye B. The Guttmacher Institute. Household characteristics and unintended pregnancy among women in Nigeria. 2006.

Rashid M, Shifa N. Mistimed and Unwanted Pregnancies in Bangladesh: Trends and Determinants, Paper presented at the annual meeting of Population Association of America (PAA), New York, March 29-31, 2007/.

Regassa N and Kebede T, A population based study on unintended pregnancy among married women in a district in Southern Ethiopia Journal of Geography and Regional Planning Vol. 4(US Global Health Policy, 2010), pp. 417-427, July 2011 Available online at http:/ / www.academicjournals.org/JGRP ISSN 2070-1845 @2011 Academic Journals Accepted in 29 April, 2011

Siddhartha A, Sethi V, Srivastore K, Jha K, Baqhi AH. Birth Preparedness and Complication Readiness among Slum woman Indory city, India's Health Pop Nutr. 2010 August; 28: 383-361.

Singh S, Sedgh, G. Hussain R. Unintended Pregnancy: Worldwide Levels, Trends and Outcomes, Studies in Family Planning. 2010, 41:4, pp. 241-250.

Singns S, Wulf B, Hussien R, Bankole A, Sedgh G. Decade of uneven progress, New York: Guttmacher Institute. Abortion World Wide, 2009. (Singns et al., 2009) E-mail: negyon@yahoo.com.

United Nations: Millennium Development Goals Report. New York: 2008:24-25

US Global Health Policy: The U.S Government and Global Maternal, New born \&Child Health; 2010.

World Health Organization (WHO). Interventions for preventing unintended Pregnancies among adolescents (review) http:/ /apps.who.int/rhl/reviews/CD005215.pdf, retrieved 03 June 2010.

www.guttmacher.org April 2010. 